control and anæsthetized animals: while 50 per cent of the controls died within 14 days, 90 per cent of the anæstbetized rats died within the same period. Hence, if there is any lethal cumulative effect or sensitization resulting from association of urethane anæsthesia with whole-body irradiation, it can only be observed within a range close to the L.D. 50/14 days. If, however, Hawkins and Murphy's test of mortality was the absolute lethal dose, the cumulative effect would have seemed important, since a dose of X-rays, two-thirds of the absolute lethal dose, would have produced in urethanized animals about the same effect as the absolute lethal dose in control rats.

To determine whether urethane anæsthesia sensitizes to X-rays, or acts cumulatively, experiments should be carried out by administering urethane after irradiation. Further research is proceeding along these lines.

Cancer Institute,

University, Brussels. July 31. ${ }^{2}$ Paterson, E., Ap Thomas, I., Haddow, A., and Watkinson, J.,
Lancet, 1, 677 (1946).

' Vannotti, A., Helv. Med. Acta, 14, 475 (1947).

${ }^{3}$ Dustin, P., and Simon, S., Bull. Soc. Belge de Radiol., 31, 149 (1948).

- Hawkins, J., and Murphy, J., J. Exp. Med., 42, 609 (1925).

'Paterson, E., Ap Thomas, I., Haddow, A., and Watkinson, J., "Approaches to Tumour Chemotherapy", 401 (1947).

- Ellinger, F., Radiology, 44, 125 (1945).

\section{A Contracture in Isolated Mammalian Muscle}

Recentuy, Goffart and Brown 1 have shown that the effectiveness of adrenaline in increasing the twitch tension of the isolated rat's diaphragm preparation is inversely proportional to the amount of potassium ion in the bath. In continuation of these experiments, I have been studying the responses of the rat's diaphragm preparation immersed in potassium. freo Tyrode's solution.

Administration of adrenaline $\left(1: 10^{5}-1: 10^{8}\right)$ causes the usual increase in twitch tension, but this may be followed by a progressive delay in relaxation. The delayed relaxation of the muscle shows itself in the first place by a reduction of the 'overthrow' of the light spring-loaded lever used for recording. The 'overthrow' is usually increased during the potentiation of twitch tension, which is the first effect of adrenaline. If the fluid in the bath is left unchanged, the 'overthrow' is seen gradually to decline, until, some $20 \mathrm{~min}$. after giving adrenaline, relaxation is clearly diphasic, a rapid initial phase being followed by a slow return of the lever to the base line. The first phase of relaxation then becomes shorter, and the slow phase starts nearer the peak of the contraction curve. The delayed relaxation is not accompanied by conducted repetitive action potentials, and appears, therefore, to be of the nature of a true contracture.

The only observed changes in action potential were similar to those described by Brown, Bülbring and Burns $^{2}$. The contracture can be produced in fully curarized muscle stimulated directly and appears, therefore, to be of purely muscular origin. It is increased by increasing the calcium chloride content of the bath fluid from the normal 0.02 per cent to 0.06 per cent, and is at first increased and then suppressed by addition of potassium chloride to give a final concentration of 0.04 per cent. Although the contracture can be generally produced by addition of adrenaline, the latter is not invariably necessary, since prolonged stimulation of a preparation in potassium-free Tyrode's solution may produce it; adrenaline appears to accelerate the process. The contracture is increased by using lower frequencies of stimulation ( $<1$ in 10 sec.) and may be suppressed by increasing the frequency of stimulation from 1 in 10 sec. to 1 per sec. High concentrations of atropine and quinine $\left(1: 10^{4}\right)$ eventually suppress the contracture, and it is also very sensitive to changes in temperature: cooling by $0.5^{\circ} \mathrm{C}$. may increase it, and warming the preparation by $1^{\circ} \mathrm{C}$. may remove it.

\section{Physiological Laboratory, \\ Institut Léon Fredericq, University of Liège. Aug. 18.}

M. Goffart

\section{'Goffart, M., and Brown, G. L., C.R. Soc. Biol., Paris, 141, 958(1947) ${ }^{2}$ Brown, G. L., Bülbring, E., and Burns, B. D., J. Physiol., 107, 115 (1948). \\ Utilization of Folic Acid Conjugate in Man}

Heinle and Welch ${ }^{1}$ have already made some observations on the utilization of folic acid conjugate. They did not observe formation of free folic acid from pteroyl-hepta-glutamic acid after incubation of the latter product with normal gastric or duodenal juice.

We have repeated this investigation and have found that the hepta conjugate is altered by normal gastric juice, although no free folic acid could be demonstrated (Buyze and Engel²).

If the incubation product of gastric juice on folic acid conjugate from yeast is incubated with rat liver conjugase prepared according to Mims, Totter and Days, no free folic acid was formed. This was not due to conjugase inhibitors present in gastric juice or yeast extract, as has been demonstrated ${ }^{2}$. This alteration of folic acid hepta conjugate into another 'conjugate' by normal gastric juice was not brought about by gastric juice of pernicious anæmia patients. The gastric juice of a sprue patient behaved like a normal human gastric juice in this respect. Normal duodenal juice was not active against pteroyl-heptaglutamic acid or the conjugate formed by the gastric juice.

Olson, Fager, Burris and Elvehjem have demonstrated that pteroyl-glutamic acid was present in rat liver not only in the form of its hepta conjugate but also in another conjugated form. It was possible to obtain free pteroyl-glutamic acid from the latter by incubation with liver homogenate. It appeared that from the gastric juice incubation product also free folic acid could be obtained by incubation with rat liver homogenate at $p \mathrm{H} 7$.

\section{H. G. BuYzE \\ Chr. Engel}

Central Institute for Nutrition Research T.N.O., Utrecht.

${ }^{1}$ Heinle, R. W., and Welch, A. D., Ann. N.Y. Acad. Sci., 48, 343 (1946). ${ }^{2}$ Buyze, H. G., and Engel, Chr., Biochim. et Biophys. Acta, 2, 217 (1948).

${ }^{3}$ Mims, V., Totter, J. A., and Day, P. L., J. Biol. Chem., 155, 401 (1944).

+ Olson, O. E. Fager, E. E. C., Burris, R. H., and Elvehjem, C. A. J. Biol. Chem., 174, 319 (1948). 